\title{
Executive functioning and dysfunctional schema modes in individuals with frontal lobe lesion and temporal lobe epilepsy; mega case analysis
}

\begin{abstract}
The present study was to investigate the executive functioning like selective attention, cognitive flexibility, processing speed and executive processing abilities in individuals with frontal lobe lesion and temporal lobe epilepsy by using a tool Stroop Neuropsychological Screening Test. ${ }^{1}$ The study also tried to explore emotional problems, cognitive state, specific behavioral responses and coping strategies of individuals with frontal lobe lesion and temporal lobe epilepsy. The present study was also designed to develop the reflective understanding of dysfunctional and healthy modes of individuals of frontal lobe lesion and temporal lobe epilepsy measure through Schema Mode Inventory Urdu version. ${ }^{2}$ The sample of the present study consisted of 08 cases 04 cases related to frontal lobe lesion and 04 cases of temporal lobe epilepsy. Our finding indicated that the individuals of frontal lobe lesion and temporal lobe epilepsy were found significantly engaged in dysfunctional modes, such as Child Modes, Maladaptive and Punitive Parents Modes. On Stroop Test the Standard Deviation of individuals with frontal lobe lesion (74.18) and temporal lobe epilepsy (59.25) both the values are below the standard value (98) which shows the significant level. The Stroop Test measure executive functioning like selective attention executive processing, cognitive flexibility and inhibition control all these qualities are low and poor in individuals with frontal lobe lesion and temporal lobe epilepsy. The individuals with frontal lobe lesion and temporal lobe epilepsy were engaged in dysfunctional modes such as Child Modes, Maladaptive and Punitive Parent Modes are positively associated with executive functioning. Individuals with dysfunctional schema modes are lower score on Stroop test.
\end{abstract}

Keywords: executive functioning, dysfunctional schema modes, frontal lobe lesion, temporal lobe epilepsy
Volume 5 Issue I - 2016

\author{
Sabir Zaman, Muhammad Tahir Khalily \\ Department of Psychology, International Islamic University \\ Islamabad, Pakistan
}

Correspondence: Sabir Zaman, Department of Psychology, International Islamic University Islamabad, Pakistan, Email sabirpsy0@gmail.com

Received: September 07, 2015 | Published: January 12, 2016

\section{Introduction}

Executive functioning is the brain ability to absorb information, interpret this information and make decision based upon this information. The executive function brain controlled functions that guide various functions of the body such as planning, problem solving, paying attention, organizing and directing the body to carry out the daily activities, and all theses function depends greatly to the frontal lobe of the brain.

A good executive function depends on healthy frontal lobes, which are located in the top front part of brain, right behind the forehead. The frontal lobes have control over many body functions. This part of the brain develops through adolescence and into adult life. The dysfunctional schema modes consist of maladaptive punitive parent and dysfunctional coping style. It is a part of the schema modes. Schema Modes are the emotional expression and the cognitive states of individuals and their coping strategies and responses which they have experience from movement to movement. The schema modes reflect state constructs as they are dependent on the situation an individual is in and are strongly related to the current emotional state of the patient. ${ }^{3}$ A schema mode is developed during the childhood and adolescence. The schema modes has well arranged limited information and experience and gradually developed. The modification and expansion in schema modes occur throughout one's lifetime. The schema modes are self perpetuating and very difficult to modify or change it. A lot of our schema modes are triggered by the life situations, circumstances, and the life events and activities that we are too sensitive to these activities and the individuals may swing in between or may shift from one schema modes to another. Several our schema modes excessively react to situations or events and are active in ways that is hurting to us.

Individual have several modes and may switch between them in ways that are confusing for other people. The schema Modes are grouped into four major categories or domains; Healthy Adult mode, Child modes, Maladaptive Dysfunctional Coping, and Dysfunctional Parent. All these major modes have 14 sub schema modes are detailed in Table 1.

The human brain is one of the most complex living structure in the universe. It works more than super computer store a lot of information and control the body functions. The brain consists of four lobes. Each lobes has their own importance but the frontal lobe play key role in the brain on its unique characteristics and executive functioning. Frontal lobes primarily support higher cognitive process, executive skills and working memory, executive functioning includes planning and decision making decision, sustain awareness, attentiveness and insight. The main function of temporal lobe to analysis the auditory information and also play important role in memory and personality. Temporal lobe epilepsy related with important cognitive impairment and has difficulty to the information in long term memory.

This study explores the executive functioning like cognitive flexibility, selective attention, and executive processing ability of the individuals with frontal lobe lesion and temporal lobe epilepsy. The current study also tries to find out the dysfunctional schema 
modes like maladaptive punitive parent, and maladaptive coping style in the individuals with frontal lobe lesion and temporal lobe epilepsy. The schema modes overall consist of emotional problem and cognitive states, specific behavioral responses and the copping styles and strategies. The one of the important feature of the study to understand and explore the healthy and dysfunctional schema modes in individuals with frontal lobe lesion or temporal lobe epilepsy.

\section{Rationale of the Study}

Both frontal lobe and temporal lobe of the brain play an important role in human mental process and daily life activities and behaviors like social interaction, personality manifestation, decision making and judgments as observed. ${ }^{4}$ The research show the damage of the frontal lobe is concerned with various emotional and cognitive deficits. For instance, it has been found that frontal lobe injury affect emotional and social decision making ${ }^{5}$ result of memory destruction. ${ }^{6}$ Mood changes and deficits in executive functioning occur in frontal lobe damage. ${ }^{7}$ On other hand the temporal lobe epilepsy has also been found to limit several neurocognitive functioning among its patients. Research suggests that individuals with Temporal Lobe Epilepsy may experience problems in learning, attention, intelligence, ${ }^{8}$ and memory. ${ }^{9}$

Unlike, studies on Temporal Lobe Epilepsy, investigation of the cognitive and behavioral dysfunctions because of Frontal Lobe damage are rare. ${ }^{10}$ In addition, not much work has been done on the psychosocial problems of Frontal Lobe Lesions or Temporal Lobe Epilepsy in Pakistan. Therefore, the prime objective of the present study was designed to explore executive functioning and the emotional and cognitive states, behavioral responses, and the coping strategies of the individuals with frontal lobe lesion and temporal lobe epilepsy. The second objective of the present was to understand and explore the healthy and dysfunctional modes of the diagnosed individuals.

The current study is very important because it will provide and may assist groundwork and possible strategies to enhance the psycho-social functioning of individuals damaged by frontal lobe and temporal lobe injuries. It is believed that the present study will be helpful to understand the problems related to neurocognitive and the problems associated with frontal lobe and temporal lobe dysfunction among Pakistani patients. Lastly, the study will add to the existing literature on the neuropsychological profiles of individuals with these problems.

\section{Case Studies of Frontal Lobe}

Case 1: A 42year old woman was admitted to the hospital due to severe previous history of headache, vomiting and fits. She was house wife and the mother of three children. The fits episodes occur from time to time. Presently she has no physical disabilities. She has no previous history of trauma and other physical disease. She had Glasgow coma score $15 / 15$. She has fully aware about their environment. The MRI report of the patient shows are well defined extra axial hyper dense lesion involving right frontal parietal region with focal thickening of adjacent calvarium and significant post contrast enhancement most likely meningioma. Two psychometric were administered to assess personality and coping strategies (Schema Mode Inventory) SMI, executive functioning (Stroop Test).

Case 2: A 35years old married man came to the hospital with complaints of headache, vomiting and fits. He was physically well and healthy. He was shopkeeper and lived with his family. Total seven members in his family, two sons, three daughters and one wife. By occupation he was a shopkeeper. He was admitted in the hospital with complaints of severe headache, vomiting and fits. No history of loss of conscious and trauma, and no significant family history, but two year before he had came to the hospital with same complaints, he was diagnosed a lesion on right frontal parietal lobe. He was operated on that time and the Doctor advised chemotherapy after the operation, and he refused the chemotherapy after operation which cause recurrent lesion. The Doctor once again advised X-rays and MRI. The current MRI report showed recurrent onset of large well defined tabulated heterogeneously enhancing hemorrhagic mass lesion consisting of cystic, areas surrounded by significant pre lesion edema involving the right frontal parietal lobe and body of the Corpus callosum that infiltrates the inferior inter hemispheric fissure and cross the midline towards the lift side causing significant mass effect. SMI were administered to assess the personality and coping strategies and Stroop Test were administered for executive functioning of the brain.

Case 3: A 20year unmarried man was admitted in the hospital due to severe head injury following a road accident. He was second year college student. He had a Glasgow coma score of 10/15 at the of admission. Skull X-ray showed no bony injury. The C.T Scan report shows contusion of the left frontal lobe and bleed on left frontal region. He was not fully conscious for two days, after his level of consciousness started improves gradually. The psychometric was applied after two days when he recovers their conscious level. Both the psychometric SMI and Stroop Test were administered to assess the coping strategies and their executive function.

Case 4: A 25year old unmarried man-live with his parents. He was the students of Diploma of Associate Engineering. He was 2nd in birth order. He came to hospital with complaints of headache, fever, and sometime his loss their vision. He was admitted in the hospital for complete investigation and diagnosed his problems. He was fully conscious and fully aware about their environment. He had no complication in his daily activities. No significant previous history of accident or trauma. Both C.T Scan and MRI was done. The MRI report showed was report a broad based extra axial mass in the right frontal region, meningioma, metastasis, or primary brain tumor. Both psychometric SMI and Stroop test were administered.

\section{Cases of Temporal Lobe Epilepsy}

Case 5: A 32 married woman has two daughters live with his husband. She came to the hospital with the complaints of high grade fever for 10 days, vomiting, headache, and fits. She was admitted in hospital for treatment. At the time of admission the score on Glasgow coma scale was $8 / 15$. The psychometric were administered after few days when she recovers her conscious level. No family history of epilepsy and no previous of trauma. MRI report shows bilateral frontal right temporal, insular cortex and cingulated gyres, likely suggestive of herpes simple encephalitis. Schema Mode Inventory and Stroop Test were administered to assess the coping and personality and higher mental function.

Case 6: A 18years unmarried man has three brothers and three sisters. He was 3 rd in birth order. His parents are alive. He was hospitalized with complaints of fits, pain in whole body, headache, and tongue bite during fits, from the last seven years. In family history his elder sister has the same problems of fit but she never hospitalized due to lack of financial resources and hospital facilities.MRI brain showed congenital CSF \& cyst of right medial temporal lobe. Schema Mode Inventory (SMI) was administered for coping and personality and Stroop Test for higher mental functioning. 
Case 7: A 37years married man worked as a shopkeeper. He has three daughters and three sons. He was admitted in the hospital with complaints of headache dizziness, tongue biting and onset of Epilepsy for 7days. He has no significant family history of epilepsy and no history of trauma and addiction. MRI report showed right temporal parietal brain tumor with cystic \& solid component and brain edema. Both SMI and Stroop Test were administered for psychometric assessment.
Case 8: A 46year married male has two sons and one daughter. He came with complaints of fits and headache. He has previous history of fall six months back. Before this he was normal. He has no significant family history of epilepsy. The fit starts after trauma of fall.

He was fully conscious and score on Glasgow coma scale 15/15. C.T Report show left temporal lobe hemorrhage (bleed in left temporal lobe of the brain).Both the psychometrics were administered (Schema Mode Inventory \& Stroop Test.

Table I Description of SMI (Schema Mode Inventory)

\begin{tabular}{|c|c|c|}
\hline Domains & Modes & Description of Emotion \\
\hline Healthy adult & Healthy adult & $\begin{array}{l}\text { This mode perform appropriate adult functioning Such as obtaining information, evaluating, } \\
\text { problem solving, working and parenting. Taking responsibilities for choice and actions in } \\
\text { balance way pursues pleasurable adult activities such as sex, social relationship, sporting, } \\
\text { culture and service related activates. }\end{array}$ \\
\hline \multirow{6}{*}{ Child mode } & Vulnerable (VC) & $\begin{array}{l}\text { Feels like a lonely child, isolation, feeling of empty, socially unacceptable, not deserving of } \\
\text { love, Sadness, helpless and hopeless, incompetent, needy and pessimistic. }\end{array}$ \\
\hline & Angry (AC) & $\begin{array}{l}\text { Feels intensely angry, enraged, frustrated, infuriated and irritated because their emotional } \\
\text { and Physical desires are not being met. }\end{array}$ \\
\hline & Enraged Child (EC) & Experiences strong feeling of aggression that result hurting or damaging the properties. \\
\hline & Impulsive Child (IC) & $\begin{array}{l}\text { Act as a non-core wishes or impulse in selfish and uncontrolled way to get his or her own } \\
\text { way of method and no regarding of self and others. }\end{array}$ \\
\hline & Undisciplined Child (UC) & no well power to finish the routine work and boring assignment, easily frustrated. \\
\hline & Happy Child (HC) & $\begin{array}{l}\text { Feeling of love, peace, satisfaction, praised, self -confident, competent, nurture, guided, } \\
\text { optimistic, because important emotional desires presently meet. }\end{array}$ \\
\hline \multirow{5}{*}{ Maladaptive } & Complaint surrender & $\begin{array}{l}\text { Act in a submissive, obedient, encouragement or self insulting way towards other due to } \\
\text { coping (CS) fear of conflict or rejection. }\end{array}$ \\
\hline & Detached Protector (DP) & $\begin{array}{l}\text { Psychologically withdraw from the pain of the schemas by emotionally detaching, disconnect } \\
\text { emotions from others and reject their help. }\end{array}$ \\
\hline & $\begin{array}{l}\text { Detached Self Soother } \\
\text { (DSS) }\end{array}$ & $\begin{array}{l}\text { these people shut off their emotion and engage in activities that will somehow quiet } \\
\text { stimulate or distract them from felling. These behaviors usually consist of extreme working, } \\
\text { gambling, dangerous games, immoral sexual characteristics, or drug abuse and overeating } \\
\text { habit. }\end{array}$ \\
\hline & Self Aggrandizer (SA) & $\begin{array}{l}\text { Behave in competitive, grandiose, or status, totally self absorbed self, have a little feeling of } \\
\text { empathy for the others. They show the feeling of superiority. }\end{array}$ \\
\hline & Bully and Attack (BA) & $\begin{array}{l}\text { Openly hurt the people in a controlling way. They harm the other people verbally, } \\
\text { emotionally, sexually and physically. They engage in antisocial and criminal activities. }\end{array}$ \\
\hline \multirow[t]{2}{*}{ Maladaptive } & Punitive Parent (PP) & $\begin{array}{l}\text { They are angry and heated with themselves and they have the feeling that their parent did } \\
\text { not allows to express their normal needs. Sign and symptoms includes self- loathing, self } \\
\text { criticism, self destructive behaviors. }\end{array}$ \\
\hline & Demanding (DP) & $\begin{array}{l}\text { Struggle for perfectionist, avoiding time wasting, strive for high status, express their feeling } \\
\text { in spontaneously, strict rules and high standards. }\end{array}$ \\
\hline
\end{tabular}

\section{Method}

\section{Instruments}

Schema Mode Inventory and Stroop Test will be used.

Schema Mode Inventory: This short version of the Schema Mode Inventory consist of 124 items scored on six point Likert scale ranging from 'never or almost never' to 'always. The short version of SMI comprises four domains (Child, Maladaptive coping, Maladaptive Parent, Healthy Adult), and include 14 schema modes. The Urdu version of SMI is reliable and valid instrument which seems proper for assessment of Schema Modes. it can be used effectively both in clinical and academic settings. The Urdu version can help in the assessment and understanding. The SMI has good discriminate validity and moderate convergent validity, and has good internal consistency for all sub scales (Cronbach's range 0.76-0.96, means= $0.86)$

Stroop Neuropsychological Screening Test.The Stroop task has been used as an experimental measure in psychological studies for a long time, and has been adapted for clinical neuropsychological use. ${ }^{11}$ The Stroop Neuropsychological Screening Test ${ }^{12}$ is one of the versions of the Stroop Test that has been used in clinical work. Stroop Test includes two tasks" Color Task and Color Word Task. Each word stimulus is printed in an incongruent ink color. There are 112 color words in each task. In color task, subjects are first asked to read the color words as fast as possible followed by the performance of the Color Word task. In the Color-Word task subject are instructed to name the ink color as quickly as they can. Subjects have two minutes to complete each task. The score for each task is the number of correct 
responses minus incorrect responses within two minutes. Only the score from Color-Word Task is used for interpretation purposes.

\section{Participants}

In the present study mega cases were studied four of frontal lobe lesion and four of temporal lobe epilepsy. The frontal lobe lesion consist of one female and three male participant. In these four cases one patient has surgical lesion and the rest of the three had brain tumors. The temporal lobe epilepsy also consist of four cases, one female and three male participants. The age range in between 18 to 45years. All the cases were studied in the Pakistan institute of Medical Science Department of Neurosurgery.

\section{Procedures}

An informed consent was secured for each subject before starting the tests administration short version Urdu translated of the Schema Mode Inventory consist of 124 items scored on six point Likert scale ranging from "never or almost never' to 'always'. The Stroop Neuropsychological Screening Test, ${ }^{13-18}$ were also administered. They were instructed to read the items carefully before responding to each. They were also instructed not to leave any items blank. ${ }^{19-22}$

\section{Results}

In Stroop test the Color Word Score is the primary score used in interpretation. The most efficient cut off scores for color word was 98 for the age 18-49 and 61 for $50+$ age group. Scores at or below these values show high probability of association. ${ }^{23-26}$ The result score of frontal lobe lesion 74.18 and color word score on temporal lobe epilepsy is 59.25 ; both the scores values are significant which is below the standard value 98

\section{Discussion}

This present research studied the executive functioning and the dysfunctional schema modes in individuals with frontal lobe lesion and temporal lobe epilepsy. The dysfunctional schema modes have been used first time on frontal lobe lesion and temporal lobe epilepsy patients. ${ }^{27-29}$ The present study analyzed multiple cases of frontal lobe lesion and temporal lobe epilepsy in Pakistan. The study finds out currently dominated Schema Modes such as healthy and dysfunctional modes of the individuals with frontal lobe lesion and temporal lobe epilepsy.

The finding indicates that frontal lobe lesion and temporal lobe epilepsy patients has low level of executive functioning like selective attention, executive processing abilities and cognitive flexibility. This means that the individuals with frontal lobe lesion and temporal lobe epilepsy have difficulty in executive functioning like cognitive ability, perception and attention.

The result finding of the current study showed that the individuals with frontal lobe lesion mostly used the dysfunctional schema modes such as vulnerable child undisciplined child complaint surrender, detached protector, detached self soother, bully and attack, and demanding parent. The individuals of frontal lobe lesion have the feeling of loneliness, socially unacceptable and helpless and hopeless. They have the quality of undisciplined child that cannot force him/ her to finish the routine or boring task.

The study showed that the individuals with frontal lobe lesion mostly engaged and used the maladaptive coping style and strategies such as complaint surrender act in passive and fear of rejection, detached protector means withdraw emotionally from people and cut off needs and feeling.
These individuals mostly engaged in gambling, danger sports, drug abuse and overeating, the bully attack mode behave to harm people verbally, physically, emotionally and sexually. The frontal lobe lesion individuals engaged in demanding parent avoiding time wasting, strive for high status, express their feeling in spontaneously, strict rules and high standards.

The result indicated that only male patients utilized the child mode such as angry child, feel intensively angry, enraged child means feeling of anger and damage of people or objects, impulsive child to get his or her desires and wishes in selfish manners and they have punitive parent mode, self loathing and self criticism and self destructive behavior, while the result show that the female patient of frontal lobe lesion was not engage in such types of modes, (angry child, enraged child, impulsive and punitive parents).

The result of the present study shows that temporal lobe epilepsy patients utilized the several schema modes such as complaint surrender, detached protector, and detached self soother. The complaint surrender suggest act in passive, subservient, self deprecating way towards other due to fear of conflict. The detached protector (withdraw psychological from pain, disconnect emotion from others), and detached self soother suggest excessive working, gambling, dangerous sports and drugs abused.

\section{Conclusion}

The result indicate that both the frontal lobe lesion and temporal lobe epilepsy individuals low and poor performance on Stroop Test which showed that the executive functioning are lower in these individuals The result of the present study showed that the dysfunctional schema modes and dysfunctional coping strategies occurs in frontal lobe lesion and temporal lobe epilepsy. In shortly the individuals with frontal lobe lesion and temporal lobe epilepsy has low score on Stroop test means lower the executive function and engaged in dysfunctional schema modes and maladaptive coping style and strategies.

\section{Acknowledgments}

All glory is to All Almighty, The superior and sovereign who enable me to undertake my research on Schema Mode and their relation to the frontal lobe lesion: A multiple lesion case analysis. I am thankful to my supervisor, Dr. Muhammad Tahir Khalily for his guidance and useful feedback on the MS research thesis. I am special thankful to the Medical Doctors of Neurosurgery (Dr. Zafar Elahi, Dr. Sami, Dr. Adnan and Dr. Aism, and other Doctors of the Department of Neurosurgery PIMS Hospital), they helped and support me in Data collection. I am also thankful to my parents and my wife and my brothers who have provided me financial moral support during the completion of my research.

\section{Conflicts of interest}

Author declares there are no conflicts of interest.

\section{Funding}

None.

\section{References}

1. Alexander MP, Stuss DT. Disorders of frontal lobe functioning. Seminars in Neurology . 2000;20:427-437.

2. Arntz A, Klokman J, Sieswerda S. An experimental test of schema mode model of borderline personality disorder. J Behav Ther Exp Psychiatry . 2005;36(3):226-239. 
3. Awh E, Jonides J, Smith EE, et al. Dissociation of storage and rehearsal in verbal working memory: Evidence from PET. Psychological Science. 1996;7:25-31.

4. Atkinson RC, Shiffrin RM. Human memory: A proposed system and its control processes. In: Spence K \& Spence J (Eds.), The psychology of learning and motivation. Academic Press. 1968;2:89-195.

5. Baddeley AD. Working memory. Oxford University Press, Oxford. 1986.

6. Baldo JV. Spatial and object working memory in patients with lateral prefrontal cortex lesions. University of California Press, Berkeley, USA. 1997.

7. Bamber M. The good, the bad and defenseless Jimmy- A single case of schema mode therapy. Journal of Clinical Psycholology and Psychotherapy. 2008;11(6):425-438.

8. Bechara A, Damasio AR, Damasio $\mathrm{H}$, et al. Insensitivity to future consequences following damage to human prefrontal cortex. Cognition. 1994;50:7-15.

9. Clark L, Manes F, Antoun N, et al. The contributions of lesion laterality and lesion volume to decision-making impairment following frontal lobe damage. Neuropsychologia. 2003;41(11):1474-1483.

10. Chayer C, Freedman M. Frontal lobe functions. Curr Neurol Neurosis Rep. 2001;1(6):547-552.

11. Koechlin E, Ody C, Kouneiher F. The architecture of cognitive control in the human prefrontal cortex. Science. 2003;302(5648):1181-1185.

12. Daumas-Duport C, Scheithauer BW, Chodkiewicz JP, et al. Dysembryoplastic neuroepithelial tumor: a surgically curable tumor of young patients with intractable partial seizures. report of thirty-nine cases. Neurosurgery. 1988;23(5):545-556.

13. Engel J. Surgical treatment of the epilepsies. New York, USA. 1993

14. Goldberg RF, Perfetti CA, Fiez JA, et al. Selective Retrieval of Abstract Semantic Knowledge in Left Prefrontal Cortex. J Neurosci. 2007;27(14):3790-3798.

15. Golden CJ, Jackson ML, Peterson-Rohne A, et al. Neuropsychological correlates of violence and aggression: A review of the clinical literature. Aggression and Violent Behavior. 1996;1(1):3-25.
16. Goldstein K. The mental changes due to frontal lobe damage. Journal of Psychology. 1944;17(2):187-208.

17. Hall HV. Criminal-forensic neuropsychology of disorders of executive functions. In: Hall HV \& Sbordone RJ (Eds.), Disorders of executive functions: Civil and criminal law applications. FL: PMD Publishers. 1993. p.37-77.

18. Kandel E, Freed D. Frontal-lobe dysfunction and antisocial behavior: A review. J Clin Psychol. 1989;45(3):404-413.

19. Kwentus JA, Hart RP, Peck ET, et al. Psychiatric complications of closed head trauma. Psychosomatics. 1985;26(1):8-17.

20. Lezak MD. Neuropsychological assessment. (3rd ed), Oxford University Press, New York, USA. 1995.

21. Lund M. Epilepsy in Associatian with Imracranial TumiJllr. Copenhagen: Munksgaard. 1952.

22. Lopes da Silva FH, Witter MP, Boeijinga PH, et al. Anatomic organization and physiology of the limbic cortex. Physiol Rev. 1990;70(2): 453-511.

23. Miller L. Traumatic brain injury and aggression. Journal of Offender Rehabilitation. 1994;21(3-4):91-103.

24. Penfield W, Faulk ME. The insula; further observations on its function. Brain. 1995;78(4):445-470.

25. Silver JM, Yudofsky SC. Aggressive behavior in patients with neuropsychiatric disorders. Psychiatric Annals. 1987;17(6):367-370.

26. SO NK. Depth electrode studies in mesial temporal epilepsy. In: Luders H (ed.), Epilepsy surgery. New York, USA. 1991. p.371-384.

27. Stuss DT, Alexander MP, Palumbo CL, et al. Organizational Strategies of Patients with Unilateral or Bilateral Frontal LobeInjury In Word List Learning Tasks. Neuropsychology. 1994;8(3):355-373.

28. Tulving ES, Kapur FI, Craik M, et al. Hemispheric Encoding/Retrieval Asymmetry in Episodic Memory: Positron Emission Tomography Findings. Proceedings of the National Academy of Sciences of the United States of America no. 1994;91(6):2016-2020.

29. Wyllie E. The treatment of epilepsy: principles and practice. Lea \& Febiger, Philadelphia, USA. 1993. 